Article

\title{
Effect of Microcapsules with Different Core-Wall Ratios on Properties of Waterborne Primer Coating for European Linden
}

\author{
Xiaoxing Yan ${ }^{1,2, *}$, Lin Wang ${ }^{2}$ and Xingyu Qian ${ }^{2}$ \\ 1 Co-Innovation Center of Efficient Processing and Utilization of Forest Resources, Nanjing Forestry \\ University, Nanjing 210037, China \\ 2 College of Furnishings and Industrial Design, Nanjing Forestry University, Nanjing 210037, China; \\ wanglin@njfu.edu.cn (L.W.); qianxingyu@njfu.edu.cn (X.Q.) \\ * Correspondence: yanxiaoxing@njfu.edu.cn or yanxiaoxing@nuaa.edu.cn
}

Received: 31 July 2020; Accepted: 24 August 2020; Published: 26 August 2020

\begin{abstract}
Waterborne acrylic-resin-filled urea-formaldehyde-based microcapsules with core-wall ratios of $0.42: 1,0.50: 1,0.58: 1,0.67: 1,0.75: 1,0.83: 1$ and $0.92: 1$ were prepared via in situ polymerization. Microcapsules were added into the primer to investigate the optical and mechanical properties of the coating on European linden. The results indicated that under the condition of the same core-wall ratio, chroma differences increased gradually with increasing concentration. The coating gloss decreased with increasing concentration. The hardness of 10.0-15.0\% microcapsules increased more obviously, with the highest elongations at the break of the coating. At the 0.58:1 core-wall ratio and the $10.0 \%$ concentration, the coating adhesion was level 1 and the impact resistance was $10.0 \mathrm{~kg} \mathrm{~cm}$. Microcapsule concentration did not affect the coating's liquid resistance. The coating with $10.0 \%$ microcapsules added at a $0.58: 1$ core-wall ratio had a better self-healing property, a good stability and aging resistance. This paper lays a technical basis for the manufacturing and utilization of self-healing waterborne wood coatings.
\end{abstract}

Keywords: microcapsule; core-wall ratio; waterborne primer coating

\section{Introduction}

As a kind of green and environment-friendly renewable resource, wood is universally used in house furnishings, architecture and other fields [1]. Over long-term use, wood will be damaged to a certain degree due to the external environmental factors (moths, decay, etc.) [2]. A coating over the surface is one way to seal the wood pores, which is one of the most common solutions to this problem [3]. Waterborne wood coatings are very popular coating applications based on their advantages of nontoxic environmental conservation [4], excellent adhesion [5] and good effect after coating [6]. However, these kind of coatings also have some shortcomings. For example, it will produce microcracks in the coating due to the poor adaptability to the environment, lack of toughness [7] and the nature of wet expansion and dry shrinkage of the wood [8], which will bring a sharp downgrade in terms of mechanical properties [9] and anti-corrosion properties of the coating [10]. These reduce the service life of the wood coating [11]. Consequently-To avoid the generation of microcracks in the wood coating and improve the wood's service life-Intelligent coatings with self-healing functions have become a research hotspot recently [12], among which self-healing microcapsule technology is one of the most important ways to present the intelligent coating [13].

Ma et al. [14] smoothly prepared the oxide (GO)-modified double-walled polyurea microcapsules (GOBPM). They favorably fabricated the self-healing epoxy composite coatings with GOBPM. The results showed that the coatings with 3.0\% GOBPM added had the best self-healing efficiency, to apply in 
marine environment for improving the coating toughness. Ying et al. [15] synthesized eco-friendly microcapsules with self-healing capability via embedding 4-methyl-4H-1,2,4-triazole-3-thiol into phytic acid micelles by heating. The result showed that its self-healable ability for coating damage could be realized, ameliorating the corrosion inhibition of copper in salt medium. Saman et al. [16] prepared the microcapsules containing curing agent and chose diglycidyl ether bisphenol-A-based epoxy and pentaerythritol tetrakis as the healing agents. By embedding these microcapsules into the alkyd/methyl methacrylate (alkyd/MMA) coating, they realized the UV curable alkyd resin coating with self-healing capability. It was found that the self-healing coating can offer continual safeguard to the base material via preventing or slowing the corrosion of the metallic substrate. Above, these studies have shown that pre-embedding microcapsules into the coating can repair the microcracks of the coating to a certain extent. However, at present, the studies on self-healing of waterborne wood coatings are still relatively less.

European linden, as a commonly used wood material, has the advantages of moderate hardness, uniform and dense intercellular structure and mild wood property [17], which is not easy to crack and deform, easy to process, strong toughness and good wear resistance [18]. In the wood finishing process, the main role of primer was for matching with the filling container and dyeing process. The primer was able to strengthen adhesion to containers and avoid the coating from falling off, thus boosting subsequent processes.

In the previous study [7], urea-formaldehyde-coated epoxy microcapsule were prepared, which were added into wood coatings to form wood coatings. Microcapsules with epoxy resin as the core need to be cured by heating or add curing agent at room temperature. In this paper, waterborne acrylic resin as the core of the microcapsules is not only green and environmentally friendly, but also can be cured at room temperature, which provides a more convenient way for waterborne wood coatings. Waterborne acrylic-resin-filled urea-formaldehyde-based microcapsules were fabricated via in situ polymerization. European linden was selected as the substrate, and seven kinds of microcapsules were added into the waterborne primer with different concentrations to obtain self-healing coating. The influences of the core-wall ratio and microcapsules concentration on properties of waterborne wood coating were investigated, which established for the study of better aging resistance of the waterborne wood coatings.

\section{Materials and Methods}

\subsection{Experimental Materials}

Waterborne acrylic resin (CAS No.: 9003-01-4) was offered by Dulux Paint Co., Ltd., Shanghai, China. Urea ( $\mathrm{M}_{\mathrm{w}}: 60.06 \mathrm{~g} / \mathrm{mol}$, CAS No.: $\left.57-13-6\right)$, 37.0\% formaldehyde solution $\left(\mathrm{M}_{\mathrm{w}}: 30.03 \mathrm{~g} / \mathrm{mol}\right.$, CAS No.: 50-00-0), triethanolamine ( $\mathrm{M}_{\mathrm{w}}: 149.19 \mathrm{~g} / \mathrm{mol}$, CAS No.: 102-71-6), citric acid monohydrate (CAM, $\mathrm{M}_{\mathrm{W}}$ : $210.14 \mathrm{~g} / \mathrm{mol}$, CAS No.: 5949-29-1), sodium dodecyl benzene sulfonate (SDBS, $\mathrm{M}_{\mathrm{W}}$ : $348.48 \mathrm{~g} / \mathrm{mol}$, CAS No. 25155-30-0), anhydrous ethanol ( $\mathrm{M}_{\mathrm{w}}: 46.07 \mathrm{~g} / \mathrm{mol}$, CAS No.: 64-17-5) were supplied by Chemical Reagent Co., Ltd., Nanjing, China. Octyl alcohol $\left(\mathrm{M}_{\mathrm{W}}: 130.23 \mathrm{~g} / \mathrm{mol}\right.$, CAS No. 117-87-5) was offered by Yatai United Chemical Co., Ltd., Wuxi, China. European linden boards $(100 \mathrm{~mm} \times 65 \mathrm{~mm} \times 4 \mathrm{~mm}$, uniform material chroma) were offered by Yihua Lifestyle Technology Co., Ltd., Shantou, China. Waterborne primer was supplied by Dulux Paint Co., Ltd., Shanghai, China. The main components of waterborne primer were aqueous acrylic copolymer dispersion, matting agent, additives and water. Solid concentration of the waterborne primer was higher than $30.0 \%$.

\subsection{Preparation of Microcapsules}

The microcapsule preparation process described in this work was based on the reference [7]. A detailed list of each substance dosage for the preparation of urea-formaldehyde-based microcapsules with waterborne acrylic resin as the healing agent is shown in Table 1 . The core-wall ratio of 0.42:1, etc. refers to the mass ratio of core material (waterborne acrylic resin) to wall material (urea formaldehyde 
resin) for preparation of microcapsules. The value of core-wall ratio in Table 1 is based on the reference [19]. The preparation of microcapsules with a $0.42: 1$ core-wall ratio is described as an example. The $30.0 \mathrm{~g}$ urea formaldehyde resin was fabricated by the reaction of $20.0 \mathrm{~g}$ urea and $27.0 \mathrm{~g}$ $37.0 \%$ formaldehyde in the molar ratio of $1: 1$ in the container. The mixture was completely dissolved by stirring and triethanolamine was added slowly to adjust $\mathrm{pH}$ to about 9.0. The system was stirred without an interval at a $1200 \mathrm{rpm}$ rotational speed for $1.5 \mathrm{~h}$ in a $70{ }^{\circ} \mathrm{C}$ water bath to obtain a slightly viscous transparent urea-formaldehyde prepolymer solution, and then it was cooled to room temperature. Both $96.52 \mathrm{~mL}$ distilled water and $0.975 \mathrm{~g}$ SDBS were added in another container. The mixture was stirred until completely dissolved to obtain a $1.0 \%$ solution of SDBS as an emulsifier. The $12.5 \mathrm{~g}$ waterborne acrylic resin was added to $97.0 \mathrm{~mL}$ aqueous solution of SDBS at $1.0 \%$ concentration. The system was stirred in a $60{ }^{\circ} \mathrm{C}$ constant temperature water bath for $30 \mathrm{~min}$ at $1200 \mathrm{rpm}$ rotational speed. Then 12 drops of octyl alcohol were added for defoaming. At $300 \mathrm{rpm}$, the urea-formaldehyde prepolymer was dripped into the core material emulsion, the CAM was added gradually and stirred until completely dissolved, and the $\mathrm{pH}$ was adjusted to 2.5-3.0. Finally, the system was slowly reacted at $70{ }^{\circ} \mathrm{C}$ for $3 \mathrm{~h}$. The forming microcapsules were filtered and washed with distilled water and anhydrous ethanol to remove the emulsifier excess. Some unreacted particles can be screened out during the suction filtration, which avoids the agglomeration of microcapsules to a certain extent. Then the microcapsules were dried at $80^{\circ} \mathrm{C}$ for $4 \mathrm{~h}$ to obtain the needed powdered microcapsules with a $0.42: 1$ core-wall ratio. Moreover, after dried, the microcapsules were in powder form, which was convenient for the preparation of self-repairing waterborne coatings. Detailed preparation processes of microcapsules with other core-wall ratios were the same as that of 0.42:1.

Table 1. Detailed List of Each Substance Dosage for the Preparation of Microcapsules.

\begin{tabular}{|c|c|c|c|c|c|}
\hline Urea (g) & $\begin{array}{c}37.0 \% \text { Formaldehyde } \\
\text { Solution }(\mathrm{g})\end{array}$ & $\begin{array}{c}\text { Waterborne } \\
\text { Acrylic Resin (g) }\end{array}$ & $\begin{array}{c}\text { Sodium Dodecyl } \\
\text { Benzene Sulfonate (g) }\end{array}$ & $\begin{array}{l}\text { Distilled } \\
\text { Water (g) }\end{array}$ & $\begin{array}{l}\text { Core-Wall } \\
\text { Ratio }\end{array}$ \\
\hline 20.0 & 27.0 & 12.5 & 0.975 & 96.52 & $0.42: 1$ \\
\hline 20.0 & 27.0 & 15.0 & 1.17 & 115.83 & $0.50: 1$ \\
\hline 20.0 & 27.0 & 17.5 & 1.37 & 135.60 & $0.58: 1$ \\
\hline 20.0 & 27.0 & 20.0 & 1.56 & 154.44 & $0.67: 1$ \\
\hline 20.0 & 27.0 & 22.5 & 1.76 & 174.24 & $0.75: 1$ \\
\hline 20.0 & 27.0 & 25.0 & 1.95 & 193.05 & $0.83: 1$ \\
\hline 20.0 & 27.0 & 27.5 & 2.15 & 212.85 & $0.92: 1$ \\
\hline
\end{tabular}

\subsection{Preparation of Coatings}

Seven kinds of core-wall ratios $(0.42: 1,0.50: 1,0.58: 1,0.67: 1,0.75: 1,0.83: 1$ and 0.92:1) of microcapsules were added to the primer to prepare self-healing waterborne primer with microcapsule concentrations of $0 \%, 5.0 \%, 10.0 \%, 15.0 \%, 20.0 \%$ and $25.0 \%$, respectively. The composition is shown in Table 2. The primer was coated on European linden boards with SZQ tetrahedral fabricator (Senyuan Electric Co., Ltd., Zibo, China). The coating was then dried naturally for $30 \mathrm{~min}$, and the sample was heated to constant weight in a drying box at $35^{\circ} \mathrm{C}$ and then cooled to room temperature. Since the coated surface usually rough, it needed to be sanded to obtain a flat surface. Therefore, the coating was burnished lightly via the 800 grit sandpaper and wiped by a dry cloth to remove dust. After the above process was repeated twice, sample $1 \#$ can be obtained. In tensile test measurement, the waterborne coatings with and without microcapsules were fabricated onto glass substrates based on the same process of sample 1\#. The thickness of all the obtained waterborne coating with SZQ tetrahedral fabricator is approximately $60 \mu \mathrm{m}$. Figure 1 shows the preparation route. The 1110 samples of coatings on wood were prepared. 
Table 2. Composition of Waterborne Primer with Microcapsules.

\begin{tabular}{ccccc}
\hline Sample (\#) & $\begin{array}{c}\text { Microcapsule } \\
\text { Concentration (\%) }\end{array}$ & $\begin{array}{c}\text { Microcapsule } \\
\text { Weight (g) }\end{array}$ & $\begin{array}{c}\text { Waterborne } \\
\text { Primer Weight (g) }\end{array}$ & $\begin{array}{c}\text { Self-Healing Waterborne } \\
\text { Primer Weight (g) }\end{array}$ \\
\hline 1 & 0 & 0 & 100.0 & 100.0 \\
2 & 5.0 & 5.0 & 95.0 & 100.0 \\
3 & 10.0 & 10.0 & 90.0 & 100.0 \\
4 & 15.0 & 15.0 & 85.0 & 100.0 \\
5 & 20.0 & 20.0 & 80.0 & 100.0 \\
6 & 25.0 & 25.0 & 75.0 & 100.0 \\
\hline
\end{tabular}

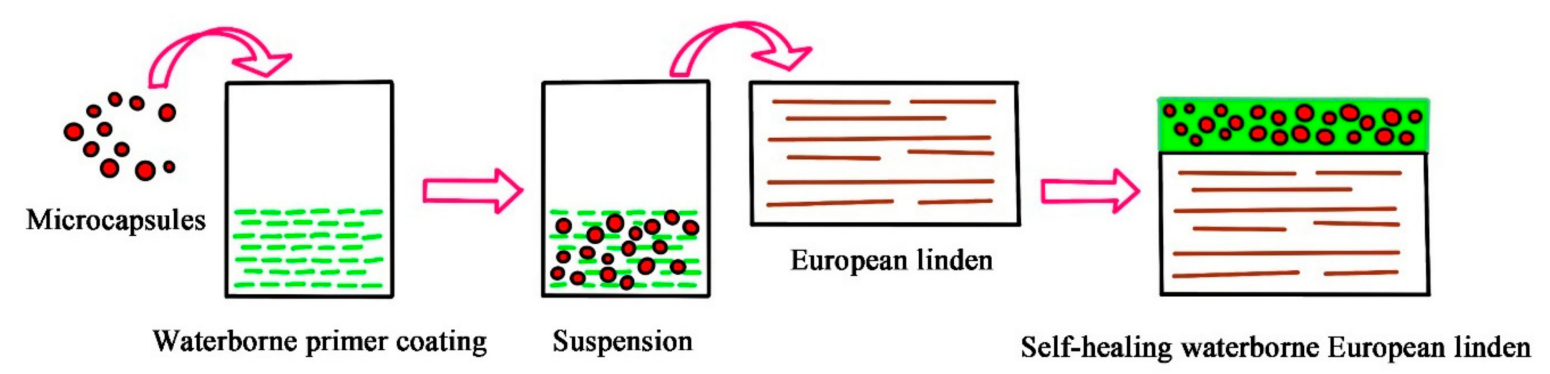

Figure 1. Preparation route of self-healing coatings and self-healing mechanism of waterborne coatings with microcapsules on European linden.

\subsection{Testing and Characterization}

The chroma values of coating were tested by HP-2136 portable chromatic aberration instrument (Hanpu Testing Instrument Co., Ltd., Shenzhen, China). The L-sign represents the brightness of the coating surface. The a-sign represents the chroma value from red to green, the b-sign represents the chroma value from yellow to blue, while the c-sign represents the saturation. The H-sign represents hue. $L_{1}, a_{1}$ and $b_{1}$ are the chroma values of one point on the coating; meanwhile, $L_{2}, a_{2}$ and $b_{2}$ are the chroma values of another point. $\Delta \mathrm{L}$ (brightness difference) $=\mathrm{L}_{1}-\mathrm{L}_{2}, \Delta \mathrm{a}$ (red-green difference) $=$ $\mathrm{a}_{1}-\mathrm{a}_{2}, \Delta \mathrm{b}$ (yellow-blue difference) $=\mathrm{b}_{1}-\mathrm{b}_{2}$. The chroma difference $(\Delta \mathrm{E})$ was computed in the light of Equation (1):

$$
\Delta \mathrm{E}=\left[(\Delta \mathrm{L})^{2}+(\Delta \mathrm{a})^{2}+(\Delta \mathrm{b})^{2}\right]^{1 / 2}
$$

The $60^{\circ}$ gloss of coatings was determined using the HG268-gloss meter (3NH Technology Co., Ltd., Shenzhen, China). Grades of $6 \mathrm{H}-6 \mathrm{~B}$ pencils were used to determine the coating hardness. The angle between the pencil and the coating was about $45^{\circ}$. The pencil was pushed forward on the coating surface at the speed of $1 \mathrm{~cm} / \mathrm{s}$ under the $1.0 \mathrm{~kg}$ load. As scratches appeared on the coatings, the coating hardness was measured. The adhesion was determined by a QFH-HG600 coating grader (Yueqing Liushi Li Chuang Measurement Equipment Firm, Zhejiang, China). The handle was held, and the multi-edge cutter was perpendicular to the board; the coating was cut at a speed of $20-50 \mathrm{~mm} / \mathrm{s}$ under uniform pressure. Afterward, this operation was repeated by rotating the setup $90^{\circ}$ to form a grid pattern. Tape was applied to the entire grid and then removed at a minimum angle. A magnifying glass was used to observe the coating damage. According to the damage degree, the adhesion level was determined. The impact resistance was measured by the QCJ impactor (Maike Instrument Equipment Co., Ltd., Dongguan, China). The sample coating was placed on the iron plate horizontally upward, and the heavy hammer was fixed at a certain height of the sliding cylinder by the control device. After the control button was pressed, the heavy hammer would fall on the punch freely. When the heavy hammer was lifted and the test panel was taken out, the deformation degree of coating surface shall be observed by a magnifying glass and the height of the heavy hammer falling on the test panel shall be recorded. Impact resistance was represented by the maximum height of the fixed weight falling on the test plate without causing damage to the coating. The 680 tests were performed for mechanical testing. 
Elongations at break were gauged with the Model AG-IC100KN precision electronic universal capability experiment machine and TRview X optical displacement meter (Shimadzu Co., Ltd., Kyoto, Japan). The coating was applied to the glass substrate and then soaked in water to remove it with a knife. Both ends of the coating were clamped by clamps to guarantee that the coating did not slid. The coating was out of shape at the tensile rate of $0.12 \mathrm{~mm} / \mathrm{min}$ and was destroyed under a certain longitudinal load. Elongation at break was computed based on the displacement length of the coating at fracture and initial length of the coating before drawing.

Liquid resistance was gauged by a $15.0 \% \mathrm{NaCl}$ solution, $70.0 \%$ medical ethanol, Whitecat Detergent containing $25.0 \%$ fatty alcohol ethylene oxide and $75.0 \%$ water (Hutchison Whitecat Co., Ltd., Shanghai, China) and red ink (Fine Stationery Co., Ltd., Shanghai, China). The first two liquids were supplied by Qingdao Haishi Hainuo Co., Ltd., Qingdao, China. After soaking in the test solutions, the filter paper was removed with a tweezer and placed in the coating test area. Samples were covered with glass cover. After $24 \mathrm{~h}$, the glass cover and filter paper were taken off. The residual liquid on the coating surface was absorbed, and the imprint and discoloration were examined. The precision contact angle measuring instrument (Swedish Attention Theta, provided by Baioulin Technology Co., Ltd., Finland, Sweden) was used to test the contact angle of the coating containing microcapsule. The test liquid was distilled water.

A ZN ultraviolet weather resistance tester (Environmental Test Equipment Co., Ltd., Nanjing, China) was used to test the coating aging and stability. The aging process under the action of natural climate is simulated in the laboratory, and the UV light with the wavelength of $280-340 \mathrm{~nm}$ is used. The light source was adopted $8 \mathrm{UV}$ fluorescent tubes with rated power of $40 \mathrm{~W}$, which were distributed on both sides of the machine, 4 on each side. The center distance of the lamp was $79 \mathrm{~mm}$. The distance between the sample surface and the UV-lamp plane was $50 \mathrm{~mm}$ and parallel. The test sample was fixed on the sample rack, facing the fluorescent lamp. When the sample holder was not filled completely, the blackboard was used to fill the sample holder and to keep the inner wall of the test chamber closed. The illumination temperature was $60^{\circ} \mathrm{C}$; the condensation temperature was $50^{\circ} \mathrm{C}$; the cycle time was $4 \mathrm{~h}$ illumination with $4 \mathrm{~h}$ condensation. The chroma value and gloss of the coating before and after aging and stability test were tested and the total testing time was $200 \mathrm{~h}$. In the aging and stability measurement, $\mathrm{L}_{1}, \mathrm{a}_{1}, \mathrm{~b}_{1} \mathrm{c}_{1}$ and $\mathrm{H}_{1}$ were the coating chroma values before aging and stability test and $\mathrm{L}_{2}, \mathrm{a}_{2}, \mathrm{~b}_{2}, \mathrm{c}_{2}$ and $\mathrm{H}_{2}$ were the chroma after aging and stability test.

The morphology of the microcapsules and the waterborne primer coating for aging resistance test measurement was analyzed by Quanta 200 environment scanning electron microscope (SEM) from FEI Company (Hillsboro, OR, USA). The optical microscope (OM) image of the microcapsule and coating was observed with a ZEISS light microscope AX10 (Carl Zeiss AG, Aalen, Germany). The coating composition was analyzed by Vertex $80 \mathrm{~V}$ infrared spectrum analyzer (Germany Bruker Co., Ltd., Karlsruhe, Germany). The test range was $4000-500 \mathrm{~cm}^{-1}$, the scanning sample was $16 \mathrm{~s}$, and the resolution was $4 \mathrm{~cm}^{-1}$. The infrared spectrum of the microcapsules were measured by potassium bromide tablet method. The specific operation steps were as follows: $200 \mathrm{mg} \mathrm{KBr}$ and 1-2 mg microcapsules were taken out and ground in an agate mortar for about 1-2 min. During grinding, the samples were scraped to the center of the mortar with a small stainless-steel shovel to grind them more finely and avoid uneven generation and scattering of particles, resulting in uneven baseline. The mold was taken out and wiped clean, and the sample was put into the medicine spoon evenly. The whole process was finished by baking with infrared lamp. The mold was placed on tablet press, screwed tightly to close the vent valve, pressurized to $20 \mathrm{MPa}$ and stayed for $1-2 \mathrm{~min}$. The bleeder valve was opened slowly to reduce the pressure to 0 . The screw was unscrewed, and the mold was taken out. The base was open, the inner module was pressed out in the opposite direction, carefully the pressed tablet was taken out with a flat chemical shovel and put into tablet holder. The infrared spectrum of coating was measured by ATR method. The coating was to place the sample on the test bench, and the sample was fixed on the top surface of ATR crystal by pressure bar. All the experiments were repeated four times with an error of less than $5.0 \%$. 


\section{Results and Discussion}

\subsection{Morphology Characterization and Chemical Composition Analysis of Microcapsules}

Scanning electron micrographs of seven kinds of microcapsules are shown in Figure 2. By comparing seven kinds of microcapsules, it was obvious that when core-wall ratio increased-That is, the concentration of the core material increased-The agglomeration the microcapsules became serious. Obvious irregular particles can be observed in the SEM of microcapsules with 0.75:1, 0.83:1 and 0.92:1 core-wall ratios (Figure 2E-G). The particle size of the microcapsules with 0.58:1 core-wall ratio was bigger than other microcapsules, but the agglomeration was less, and the morphology was better. From Figure 2, as the core-wall ratio was small, the micromorphology of the microcapsules was relatively good. When the concentration of core material was small, the wall material was relatively excessive, and the polyurea formaldehyde particles agglomerated with each other. When the concentration of the core material was large and the concentration of wall material was relatively low, some microcapsules formed at this time may have broken under the effect of shear force. At the core-wall ratio of $0.58: 1$, the amount of core-wall material was appropriate, and the structure of microcapsules was compact and even. The regular microcapsules in the SEM image were selected to calculate the particle size according to the scale. The core size and thickness of the wall for microcapsules are shown in Figure 3 and Table 3. The core size of the 0.58:1 microcapsule (Figure 3C) was about $4.74 \mu \mathrm{m}$ and the thickness of the wall was about $3.05 \mu \mathrm{m}$. In Figure 4, the particle-size distribution of the $0.58: 1$ microcapsule is shown. The microcapsules were spherical in shape with a particle size of $8-11 \mu \mathrm{m}$ and a low fragmentation rate.

Table 3. Core Size and Thickness of the Wall of Microcapsules.

\begin{tabular}{ccc}
\hline Core-Wall Ratio & Core Size $(\mu \mathrm{m})$ & Thickness of the Wall $(\mu \mathrm{m})$ \\
\hline $0.42: 1$ & $0.78 \pm 0.02$ & $1.405 \pm 0$ \\
$0.50: 1$ & $1.26 \pm 0.02$ & $2.105 \pm 0$ \\
$0.58: 1$ & $4.74 \pm 0.02$ & $3.05 \pm 0$ \\
$0.67: 1$ & $2.23 \pm 0.02$ & $2.95 \pm 0$ \\
$0.75: 1$ & $0.99 \pm 0$ & $1.77 \pm 0$ \\
$0.83: 1$ & $0.94 \pm 0$ & $1.535 \pm 0$ \\
$0.92: 1$ & $0.94 \pm 0$ & $2.32 \pm 0$ \\
\hline
\end{tabular}
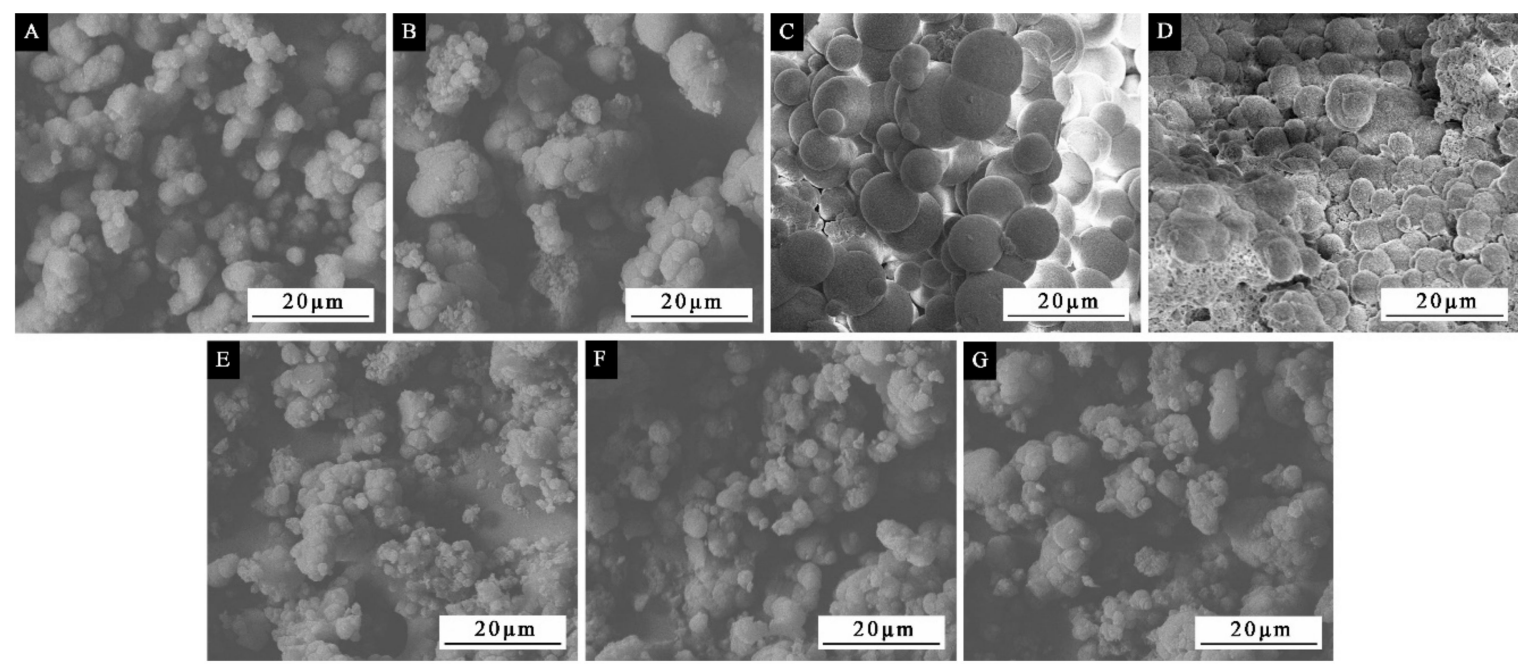

Figure 2. SEM of microcapsules. (A) $0.42: 1$; (B) 0.50:1; (C) 0.58:1; (D) 0.67:1; (E) 0.75:1; (F) 0.83:1; (G) $0.92: 1$. 

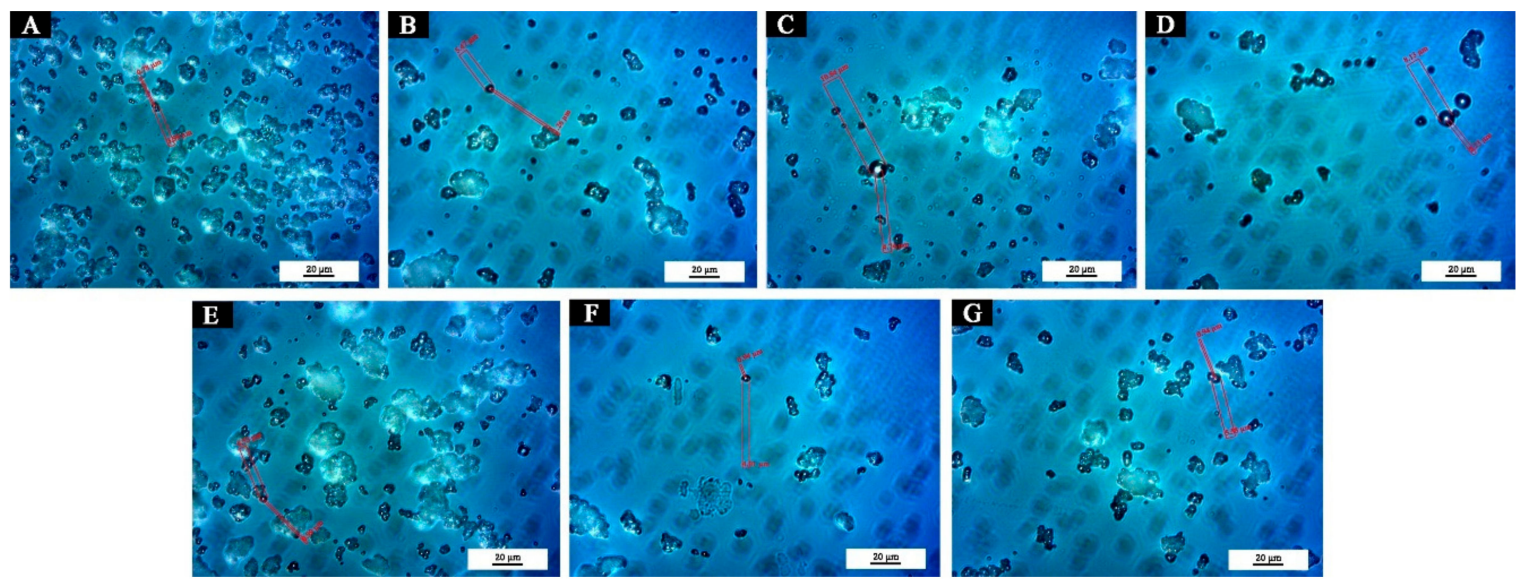

Figure 3. Optical microscope (OM) image of core size and thickness of the wall of microcapsules. (A) $0.42: 1 ;$ (B) $0.50: 1 ;$ (C) 0.58:1; (D) 0.67:1; (E) 0.75:1; (F) 0.83:1; (G) 0.92:1.

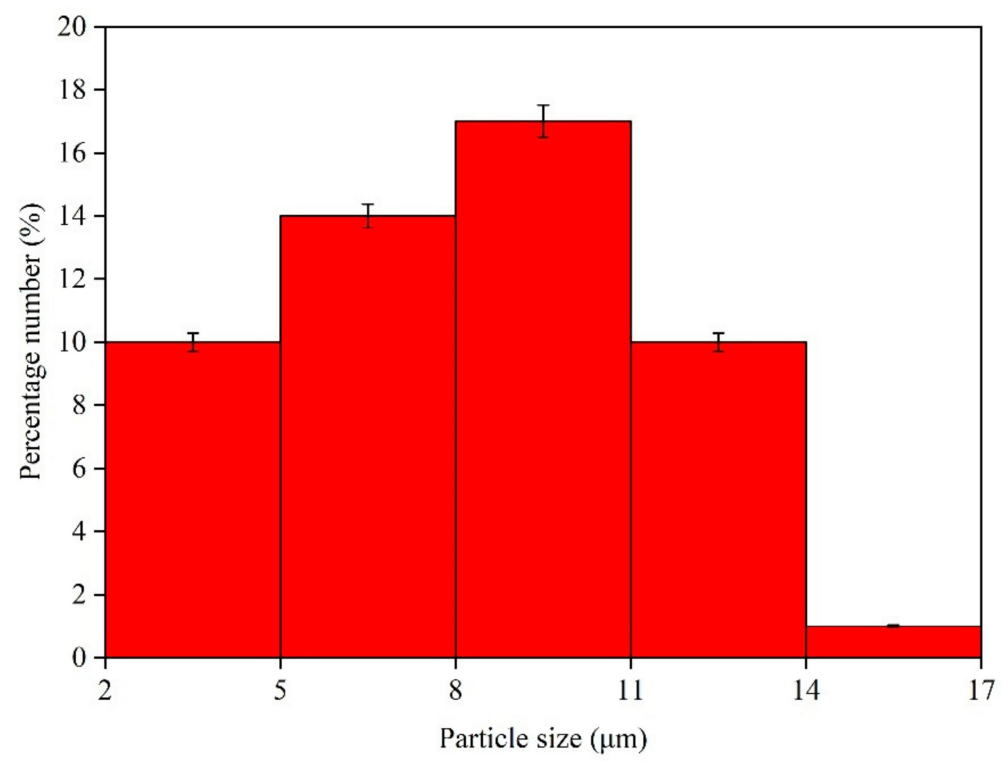

Figure 4. Particle-size distribution of the 0.58:1 microcapsule.

Figure 5 shows the infrared spectra of microcapsules. The characteristic absorption at 3360 and $1556 \mathrm{~cm}^{-1}$ were $\mathrm{N}-\mathrm{H}$ and $\mathrm{C}-\mathrm{N}$, severally. The $1639 \mathrm{~cm}^{-1}$ was the stretching vibration attributed to $\mathrm{C}=\mathrm{O}$ in urea-formaldehyde resin. At 2966 and $1447 \mathrm{~cm}^{-1}$ were the characteristic absorption belonging to $\mathrm{C}-\mathrm{H}$ and $1726 \mathrm{~cm}^{-1}$ represented the characteristic peaks of $\mathrm{C}=\mathrm{O}$ in waterborne acrylic resin. As can be seen from Figure 5, from these characteristic peaks, it can be determined that the urea-formaldehyde-based microcapsules with the waterborne acrylic resin as the core material had formed. The characteristic absorption peaks of these microcapsules were identical. The preparation of microcapsules proved that the chemical composition in these seven kinds of microcapsules did not change. 


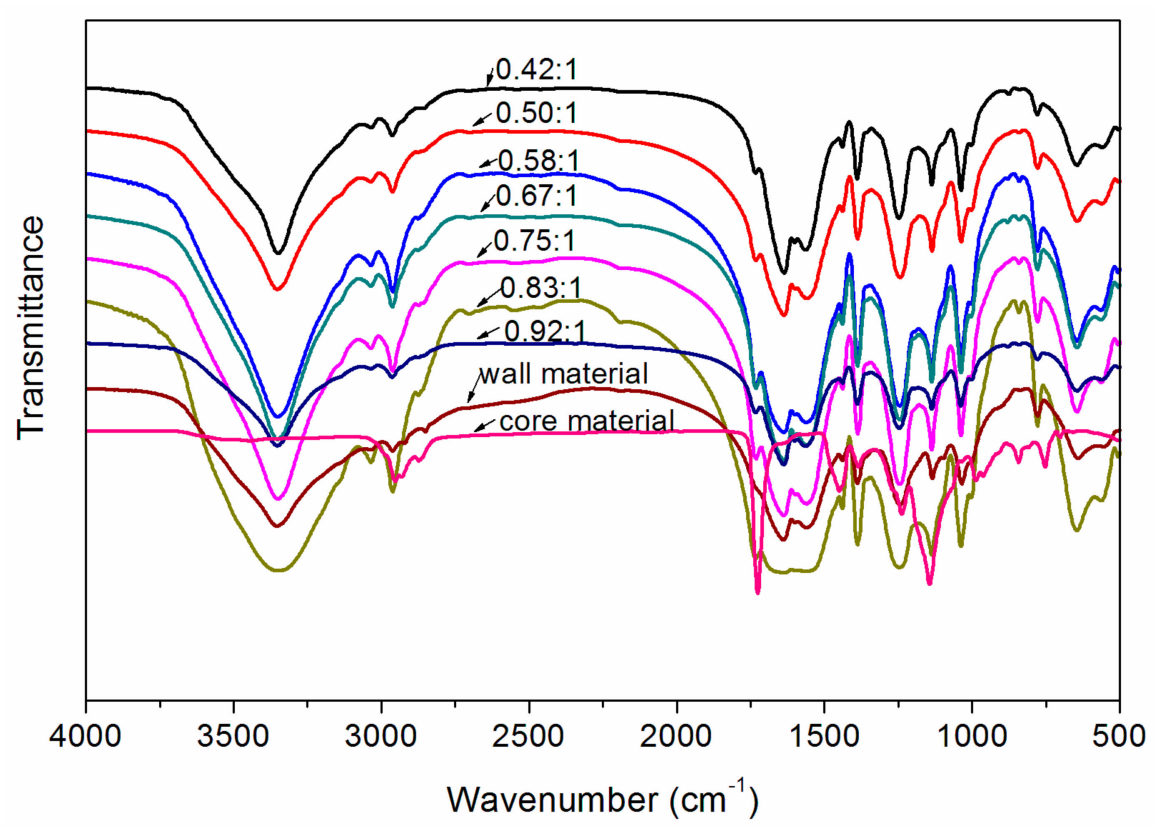

Figure 5. Infrared spectrum of microcapsules prepared via in situ polymerization.

\subsection{Effects of Concentration of on Optical Properties}

Taking the coating with 0.58:1 microcapsule as an example, the coatings with different concentrations are shown in Figure 6. The surface of the coating gradually turned white with an increasing concentration of microcapsules. This is because the microcapsules are white. The higher the concentration of microcapsules in the coating, the whiter the coating became. When the concentration was $15.0-25.0 \%$, the agglomeration of microcapsules was serious. The chroma difference of microcapsules with different concentration in the coating was measured and whether the concentration of microcapsules affected the chroma difference of coating was investigated. The chroma values of the waterborne primer coating added with different core-wall ratio microcapsules at different concentrations were tested, and the chroma difference result is shown in Figure 7. Table 4 showed the relationship between the chroma difference and the degree of discoloration. Under the condition of the same core-wall ratio, the chroma difference increased gradually with the concentration increasing. As shown in Figure 7, the higher the concentration of the microcapsule, the higher the chroma value of the coating. However, the chroma difference between the coatings with different core-wall ratios of microcapsules did not change significantly. The smaller the chroma difference was, the better the coating was. Among them, the chroma differences of the coatings with 0.50:1, 0.58:1 and 0.67:1 core-wall ratios were lower overall. It was preliminarily believed that when the concentrations of the microcapsules were $0-10.0 \%$, the microcapsule had a minimal influence on the chroma difference.

Table 4. Relationship between the Chroma Difference and the Degree of Discoloration.

\begin{tabular}{cc}
\hline Chroma Difference & Degree of Discoloration \\
\hline$\leq 1.5$ & no discoloration \\
$1.6-3.0$ & very slight discoloration \\
$3.1-6.0$ & slight discoloration \\
$6.1-9.0$ & apparent discoloration \\
$9.1-12.0$ & severe discoloration \\
$>12.0$ & complete discoloration \\
\hline
\end{tabular}



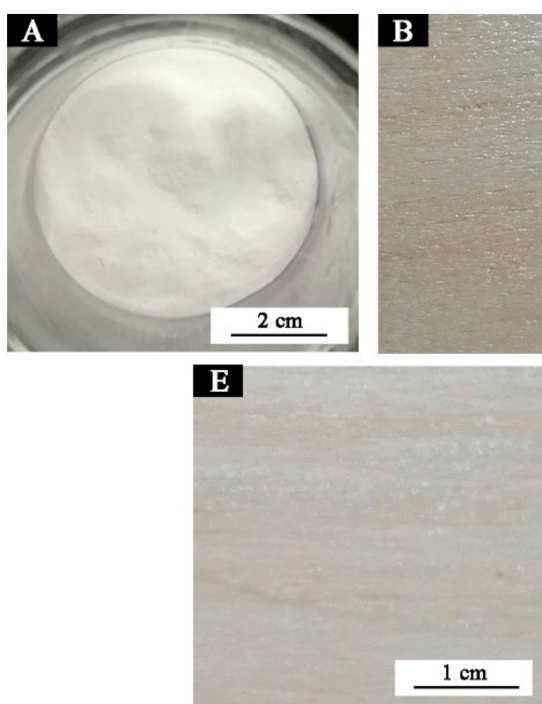

\section{B}

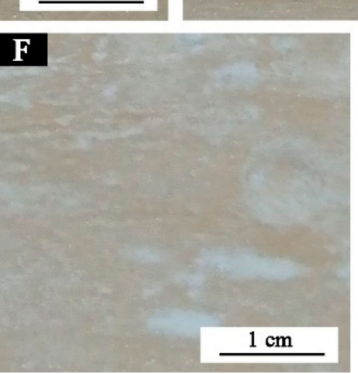

F
C

G

Figure 6. (A) Photographic images of microcapsules of 0.58:1 core-wall ratio and (B-G) the coatings with different concentrations of microcapsules of $0.58: 1$ core-wall ratio; (B) $0 \%$; (C) $5.0 \%$; (D) $10.0 \%$; (E) $15.0 \%$; (F) $20.0 \%$; (G) $25.0 \%$.

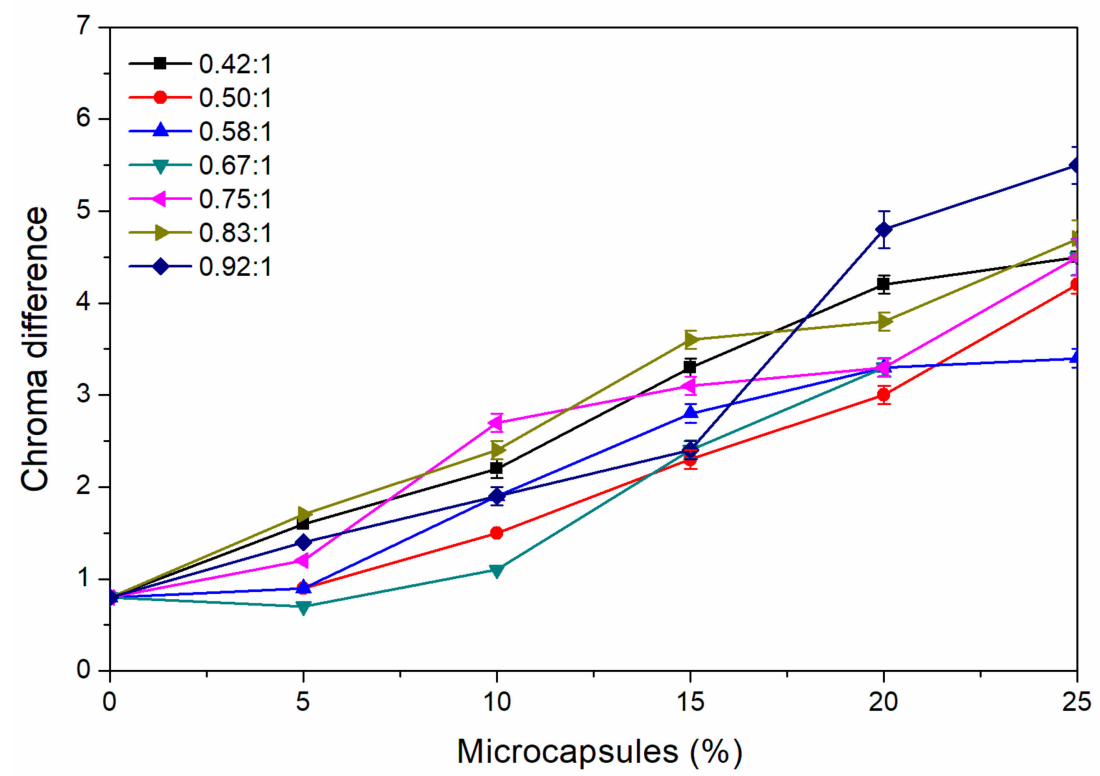

Figure 7. Effect of the concentration of microcapsules with a different core-wall ratio on the chroma difference of waterborne primer coating.

The effect of concentration of different core-wall ratio microcapsules on $60^{\circ}$ gloss of waterborne primer coating is shown in Figure 8. The coating gloss decreased with the concentration increasing. This was because the increasing concentration made the roughness of the coating surface increase and the coating surface produced diffuse reflection, thus lessening the coating gloss [20]. When the concentrations of microcapsules were $0-10.0 \%$, the effect on gloss was relatively small, and it is obvious from Figure 8 that within this range when core-wall ratio was $0.58: 1$, the gloss of the coating was relatively high. 


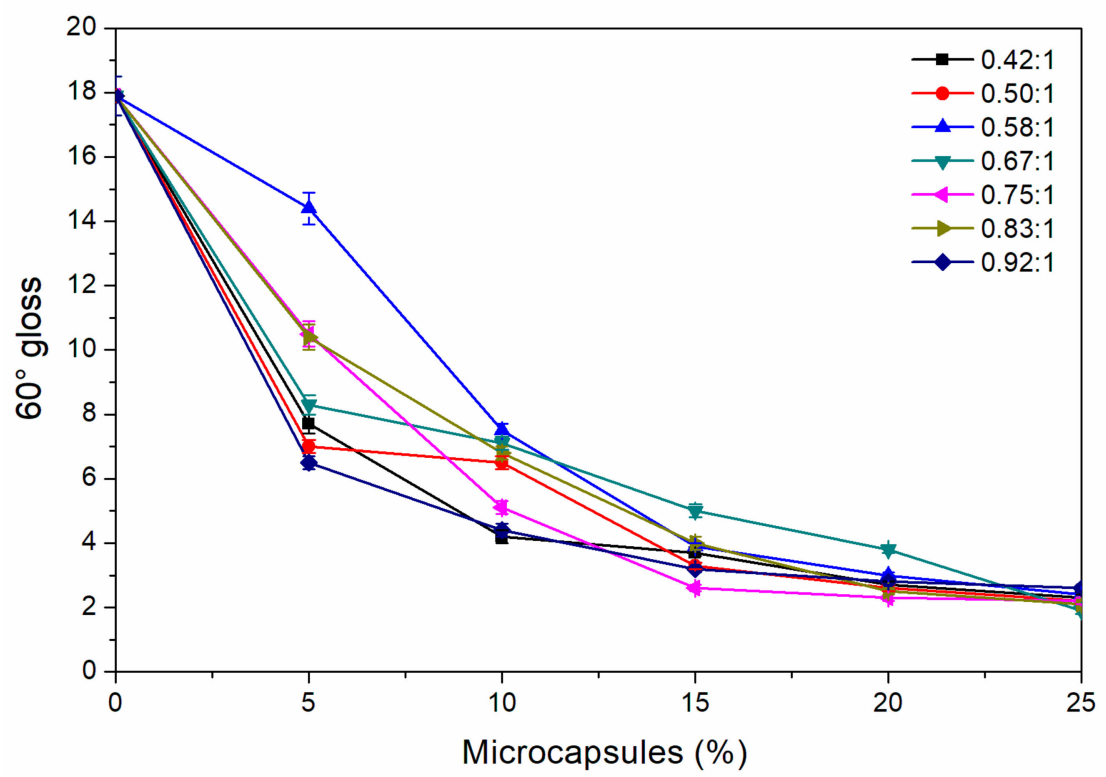

Figure 8. Effect of the concentration of microcapsules with the different core-wall ratios on the $60^{\circ}$ gloss of waterborne primer coating.

\subsection{Effects of Concentration on Mechanical Properties}

Hardness test results of the coating with different core-wall ratio microcapsules at different concentrations are shown in Table 5. When the concentration of microcapsules was in the range of $0-15.0 \%$, the hardness of coating with different core-wall ratio increased with the increase of microcapsule concentration. Under the condition of the same core-wall ratio within a certain range, the coating hardness increased with the concentration increasing. This may be due to the uniform dispersion of microcapsules in the coating and the high strength of the wall material urea formaldehyde resin, which increased the hardness of the coating [21]. Under different core-wall ratio conditions, the coating hardness at the $0.58: 1$ core-wall ratio was higher than that of other core-wall ratios. As the concentration increased to $5.0 \%$, the coating hardness increased to $\mathrm{H}$. As the concentration enhanced to $10.0 \%$, the hardness enhanced to $2 \mathrm{H}$. When the concentration continued to increase, the coating hardness increased from $2 \mathrm{H}$ to $3 \mathrm{H}$. However, as the core-wall ratio was 0.75:1, 0.83:1 and 0.92:1 and the concentration of microcapsules reached $20.0-25.0 \%$, the hardness of the coating began to decrease. The reason may be that the microcapsules in the coating agglomerated too much so that the hardness decreased [22]. It can be concluded from Figures 7 and 8 that adding too many microcapsules will affect the optical properties of the coating. Hence, in general, when the concentrations were $10.0-15.0 \%$, the coating performance was better. Moreover, compared with other core-wall ratios, the coating hardness at the 0.58:1 core-wall ratio increased more significantly.

Table 5. Effect of the Concentration of Microcapsules with the Different Core-Wall Ratios on the Hardness of Waterborne Primer Coating.

\begin{tabular}{cccccccc}
\hline \multirow{2}{*}{$\begin{array}{c}\text { Microcapsule } \\
\text { Concentration (\%) }\end{array}$} & $\mathbf{0 . 4 2 : 1}$ & $\mathbf{0 . 5 0 : 1}$ & $\mathbf{0 . 5 8 : 1}$ & $\mathbf{0 . 6 7 : 1}$ & $\mathbf{0 . 7 5 : 1}$ & $\mathbf{0 . 8 3 : 1}$ & $\mathbf{0 . 9 2 : 1}$ \\
\cline { 2 - 7 } & $\mathrm{HB} \pm 0$ & $\mathrm{HB} \pm 0$ & $\mathrm{HB} \pm 0$ & $\mathrm{HB} \pm 0$ & $\mathrm{HB} \pm 0$ & $\mathrm{HB} \pm 0$ & $\mathrm{HB} \pm 0$ \\
0 & $\mathrm{H} \pm 0$ & $\mathrm{H} \pm 0$ & $\mathrm{H} \pm 0$ & $\mathrm{H} \pm 0$ & $\mathrm{H} \pm 0$ & $\mathrm{H} \pm 0$ & $\mathrm{H} \pm 0$ \\
5.0 & $\mathrm{H} \pm 0$ & $2 \mathrm{H} \pm 0$ & $2 \mathrm{H} \pm 0$ & $2 \mathrm{H} \pm 0$ & $\mathrm{H} \pm 0$ & $2 \mathrm{H} \pm 0$ & $2 \mathrm{H} \pm 0$ \\
10.0 & $\mathrm{H} \pm 0$ & $2 \mathrm{H} \pm 0$ & $3 \mathrm{H} \pm 0$ & $2 \mathrm{H} \pm 0$ & $\mathrm{H} \pm 0$ & $2 \mathrm{H} \pm 0$ & $2 \mathrm{H} \pm 0$ \\
15.0 & $2 \mathrm{H} \pm 0$ & $2 \mathrm{H} \pm 0$ & $3 \mathrm{H} \pm 0$ & $2 \mathrm{H} \pm 0$ & $\mathrm{HB} \pm 0$ & $\mathrm{H} \pm 0$ & $2 \mathrm{H} \pm 0$ \\
20.0 & $2 \mathrm{H} \pm 0$ & $2 \mathrm{H} \pm 0$ & $3 \mathrm{H} \pm 0$ & $2 \mathrm{H} \pm 0$ & $\mathrm{HB} \pm 0$ & $\mathrm{H} \pm 0$ & $\mathrm{H} \pm 0$ \\
25.0 & & & & & & &
\end{tabular}


The effect of the concentrations of different core-wall ratio microcapsules on the adhesion of waterborne primer coating is shown in Table 6. The coating without microcapsules had the best adhesion. This is because the waterborne acrylic coating itself has a better adhesion [23]. The outcomes demonstrated that the adhesion lessened gradually as the concentration increasing under the same core-wall ratio. The coating adhesion with the 0.58:1 core-wall ratio was the best, and the coating adhesion with the $0.75: 1$ core-wall ratio was the worst. The reason maybe was that the interface adhesion between the coating and the wood became poor because of the increase of concentration [24]. As the core-wall ratio was relatively small, the microcapsule concentrations were $0-10.0 \%$, the coating adhesions were better.

Table 6. Effect of the Concentration of Microcapsules with Different Core-Wall Ratios on the Adhesion of Waterborne Primer Coating.

\begin{tabular}{cccccccc}
\hline \multirow{2}{*}{$\begin{array}{c}\text { Microcapsule } \\
\text { Concentration (\%) }\end{array}$} & $\mathbf{0 . 4 2 : 1}$ & $\mathbf{0 . 5 0 : 1}$ & $\mathbf{0 . 5 8 : 1}$ & $\mathbf{0 . 6 7 : 1}$ & $\mathbf{0 . 7 5 : 1}$ & $\mathbf{0 . 8 3 : 1}$ & $\mathbf{0 . 9 2 : 1}$ \\
\cline { 2 - 7 } & $0 \pm 0$ & $0 \pm 0$ & $0 \pm 0$ & $0 \pm 0$ & $0 \pm 0$ & $0 \pm 0$ & $0 \pm 0$ \\
0 & $1 \pm 0$ & $1 \pm 0$ & $1 \pm 0$ & $1 \pm 0$ & $1 \pm 0$ & $1 \pm 0$ & $1 \pm 0$ \\
5.0 & $1 \pm 0$ & $1 \pm 0$ & $1 \pm 0$ & $1 \pm 0$ & $2 \pm 0$ & $2 \pm 0$ & $1 \pm 0$ \\
10.0 & $1 \pm 0$ & $1 \pm 0$ & $1 \pm 0$ & $1 \pm 0$ & $3 \pm 0$ & $2 \pm 0$ & $2 \pm 0$ \\
15.0 & $2 \pm 0$ & $2 \pm 0$ & $2 \pm 0$ & $2 \pm 0$ & $4 \pm 0$ & $3 \pm 0$ & $3 \pm 0$ \\
20.0 & $3 \pm 0$ & $3 \pm 0$ & $2 \pm 0$ & $3 \pm 0$ & $4 \pm 0$ & $4 \pm 0$ & $3 \pm 0$ \\
25.0 & &
\end{tabular}

As shown in Table 7, the impact resistance of the coating with different core-wall ratios was positively correlated with the concentration of microcapsules of $0-10.0 \%$. In this concentration range, microcapsules distribute evenly in the coating, which plays a positive role in the coating. Under the same core-wall ratio, with the microcapsule concentration increasing, the impact resistance of the coating rose first and decreased later, which caused the increase of the impact strength of the coating along with the particles in the coating increasing [25]. However, the coating adhesion became poor when the microcapsule concentration became too high and it was difficult to resist the impact of external forces, which was very easy to be damaged. Compared with the coating with different core-wall ratios, the coatings at the $0.75: 1$ and $0.92: 1$ core-wall ratio had poor impact resistance. When the concentrations were $10.0-15.0 \%$, the impact resistance was stronger, but there was no obvious difference between different core-wall ratios.

Table 7. Effect of the Concentration of Microcapsules with Different Core-Wall Ratios on the Impact Resistance of Waterborne Primer Coating.

\begin{tabular}{|c|c|c|c|c|c|c|c|}
\hline \multirow{2}{*}{$\begin{array}{c}\text { Microcapsule } \\
\text { Concentration (\%) }\end{array}$} & \multicolumn{7}{|c|}{ Impact Resistance (kg cm) } \\
\hline & $0.42: 1$ & $0.50: 1$ & $0.58: 1$ & $0.67: 1$ & $0.75: 1$ & $0.83: 1$ & 0.92:1 \\
\hline 0 & $5.0 \pm 0.1$ & $5.0 \pm 0.1$ & $5.0 \pm 0.1$ & $5.0 \pm 0.1$ & $5.0 \pm 0.1$ & $5.0 \pm 0.1$ & $5.0 \pm 0.1$ \\
\hline 5.0 & $7.0 \pm 0.1$ & $8.0 \pm 0.2$ & $7.0 \pm 0.1$ & $8.0 \pm 0.2$ & $7.0 \pm 0.1$ & $7.0 \pm 0.1$ & $9.0 \pm 0.2$ \\
\hline 10.0 & $12.0 \pm 0.4$ & $12.0 \pm 0.4$ & $10.0 \pm 0.3$ & $10.0 \pm 0.3$ & $7.0 \pm 0.1$ & $10.0 \pm 0.3$ & $10.0 \pm 0.3$ \\
\hline 15.0 & $12.0 \pm 0.4$ & $12.0 \pm 0.4$ & $12.0 \pm 0.4$ & $10.0 \pm 0.3$ & $8.0 \pm 0.2$ & $13.0 \pm 0.5$ & $8.0 \pm 0.2$ \\
\hline 20.0 & $8.0 \pm 0.2$ & $12.0 \pm 0.4$ & $10.0 \pm 0.3$ & $15.0 \pm 0.5$ & $8.0 \pm 0.2$ & $13.0 \pm 0.5$ & $8.0 \pm 0.2$ \\
\hline 25.0 & $8.0 \pm 0.2$ & $9.0 \pm 0.2$ & $10.0 \pm 0.3$ & $12.0 \pm 0.4$ & $8.0 \pm 0.2$ & $12.0 \pm 0.4$ & $8.0 \pm 0.2$ \\
\hline
\end{tabular}

From the hardness, adhesion and impact test results, the coating test results with the $0.75: 1$, 0.83:1 and 0.92:1 core-wall ratios were slightly poor. The effect of the concentration of microcapsules with 0.42:1, 0.50:1, 0.58:1 and 0.67:1 core-wall ratio on the elongation at break is further studied in Figure 9. At the same core-wall ratio, with the concentration increasing, elongation at break rose first and lessened later. As the concentrations were $10.0-15.0 \%$, the elongation at break was the highest. Moreover, the elongation at the break of the coating with a 0.58:1 core-wall ratio was higher than that with other core-wall ratios. 


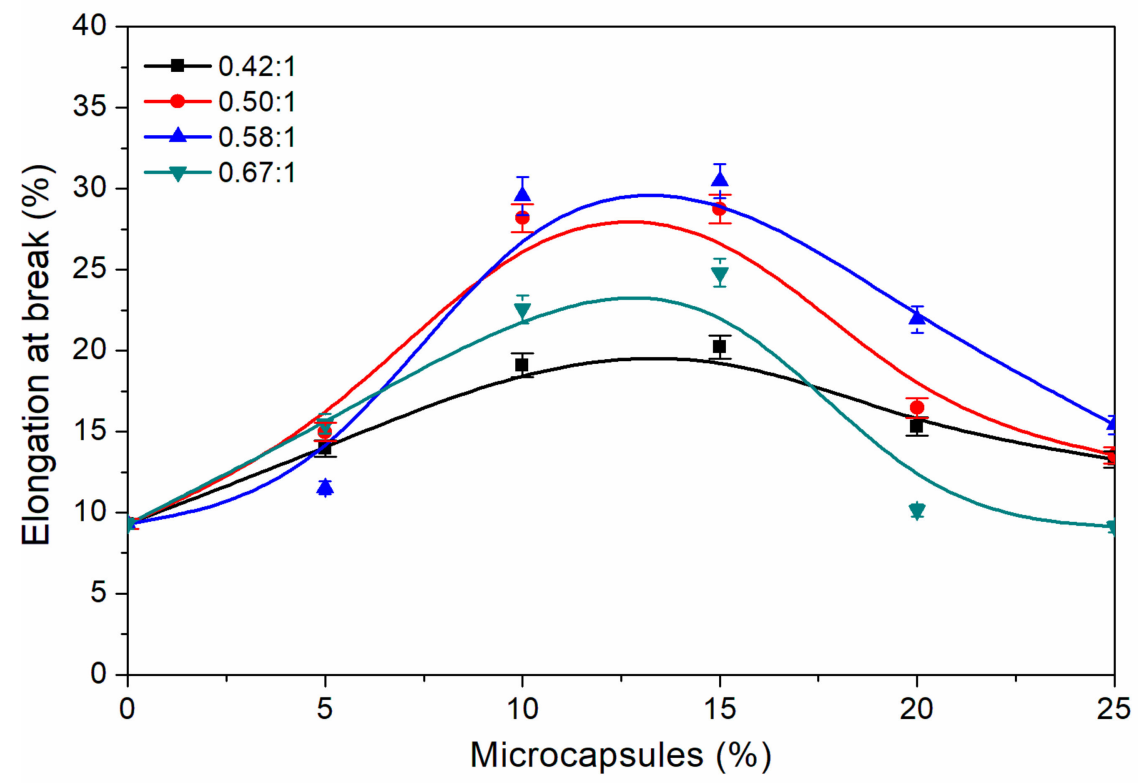

Figure 9. Effect of the concentration of microcapsules with different core-wall ratios on the elongation at break of waterborne primer coating.

\subsection{Effects of Concentration on Liquid Resistance and the Water-Contact Angle}

The core-wall ratio of 0.58:1 had a better effect on the overall performance of the primer coating than that of other core-wall ratios by comparing the optical and mechanical properties. The sample with 0.58:1 microcapsule had higher gloss, better mechanical properties and smaller color difference than other samples. Therefore, the liquid resistance of the waterborne primer coating on the European linden surface with $0.58: 1$ core-wall ratio was tested. Table 8 was the liquid resistance level result of the waterborne primer coating. Under the $0-25.0 \%$ microcapsule concentration, the coating had a resistance level of 1 to $\mathrm{NaCl}$, ethanol and detergent and there was no obvious mark on the coating surface. However, the resistance of the coating to red ink was level 3, along with the obvious mark on the coating surface. The reason may be that red ink was more permeable than other liquids. The result turned out to be that the microcapsule concentration did not affect the coating liquid resistance. The addition of microcapsules did not reduce the red ink resistance of the coating.

Table 8. Effect of the Concentration of Microcapsules with 0.58:1 Core-Wall Ratio on the Liquid Resistance Level of Waterborne Primer Coating.

\begin{tabular}{ccccc}
\hline \multirow{2}{*}{$\begin{array}{c}\text { Microcapsule } \\
\text { Concentration (\%) }\end{array}$} & \multicolumn{3}{c}{ Liquid Resistance Level (Level) } \\
\cline { 2 - 5 } & $\mathrm{NaCl}$ & Ethanol & Detergent & Red Ink \\
\hline 0 & $1 \pm 0$ & $1 \pm 0$ & $1 \pm 0$ & $3 \pm 0$ \\
5.0 & $1 \pm 0$ & $1 \pm 0$ & $1 \pm 0$ & $3 \pm 0$ \\
10.0 & $1 \pm 0$ & $1 \pm 0$ & $1 \pm 0$ & $3 \pm 0$ \\
15.0 & $1 \pm 0$ & $1 \pm 0$ & $1 \pm 0$ & $3 \pm 0$ \\
20.0 & $1 \pm 0$ & $1 \pm 0$ & $1 \pm 0$ & $3 \pm 0$ \\
25.0 & $1 \pm 0$ & $1 \pm 0$ & $1 \pm 0$ & $3 \pm 0$ \\
\hline
\end{tabular}

Figure 10 is the photographic images of distilled water-contact angle measurements of the $0.58: 1$ microcapsule-primer coated surface. As the concentration of microcapsules increased from $0 \%$ to $10.0 \%$, the contact angle of water increased from $46.7^{\circ}$ to $68.6^{\circ}$, and the water resistance was enhanced. However, when the concentration of microcapsules increased to $20.0 \%$, the contact angle decreased from $68.6^{\circ}$ to $58.4^{\circ}$ due to the agglomeration of microcapsules. If the concentration of microcapsules continued to increase, the contact angle would increase to $83.7^{\circ}$, which may be due to the formation of 
micro convex rough surface of particles, which would enhance the water resistance [26]. However, the increase of the roughness of the coating would affect the smoothness of the coating. In terms of contact angle, the contact angle of coating with 5.0-25.0\% microcapsules is larger than that without microcapsules. Large contact angle indicates poor wettability and good liquid resistance.

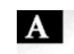

A
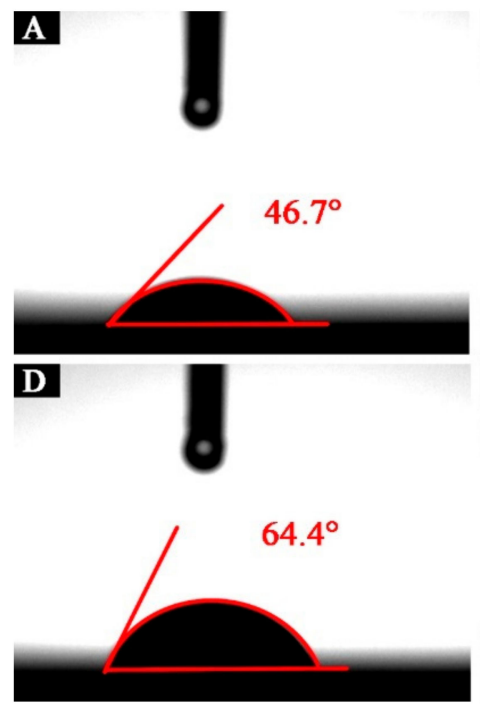

B

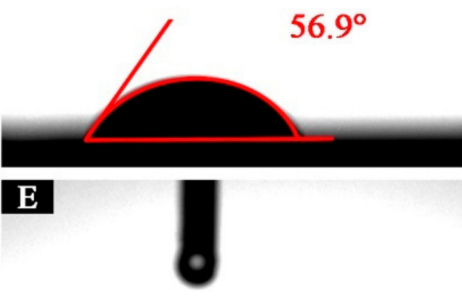

$58.4^{\circ}$
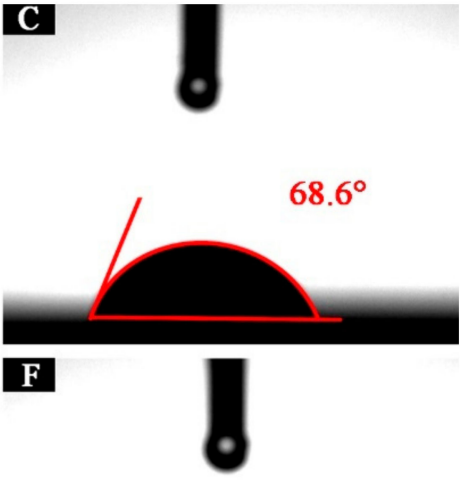

$83.7^{\circ}$
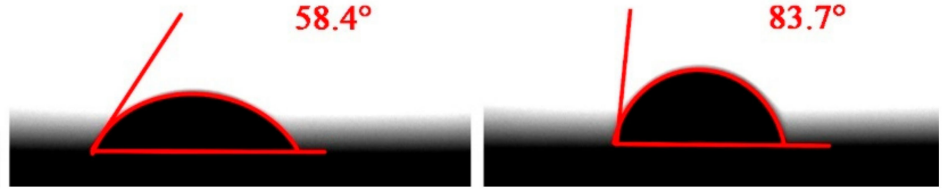

Figure 10. Photographic images of distilled water-contact angle measurements of the $0.58: 1$ microcapsule-primer coated surface. (A) $0 \%$; (B) $5.0 \%$; (C) $10.0 \%$; (D) $15.0 \%$; (E) $20.0 \%$; (F) $25.0 \%$.

\subsection{Morphology Characterization and Chemical Composition Analysis of the Coating}

According to the above experimental results, it can be concluded that at the $0.58: 1$ core-wall ratio and the concentration was $10.0 \%$, the overall performances of these coatings were better. The SEM waterborne primer coating with the 0.58:1 core-wall ratio is shown in Figure 11. Apparently, the coating without microcapsules had a smooth surface. The coating with $5.0 \%, 10.0 \%$ and $25.0 \%$ microcapsules had some particles to a certain extent, and the particles were evenly distributed when the concentration was small. However, with the concentration increased, the particles increased significantly, and the agglomeration was more serious at $25.0 \%$. This also led to the chroma difference increased and gloss lessened as the increase of microcapsule concentration at the $0.58: 1$ core-wall ratio for the increased diffuse reflection of the coating surface [20]. The cross-sectional SEM micrographs of the coatings with $10.0 \%$ concentration of the $0.58: 1$ microcapsule is shown in Figure 12. Observations of the cross-sectional SEM showed that $10.0 \%$ microcapsules were evenly distributed in the coating and not impregnated in the wood structure [27].

Figure 13 shows the infrared spectra of coating added with different concentrations of core-wall ratio of the $0.58: 1$ microcapsule. In the infrared spectrum of the microcapsules, the $\mathrm{N}-\mathrm{H}$ absorption at $3360 \mathrm{~cm}^{-1}$ belonged to the functional group of urea-formaldehyde resin. The special absorption around, 2865 and $1447 \mathrm{~cm}^{-1}$ were characteristic absorptions of $\mathrm{C}-\mathrm{H} .1639 \mathrm{~cm}^{-1}$ was put down to the stretching vibration of $\mathrm{C}=\mathrm{O}$ in urea-formaldehyde resin in wall material and the corresponding urea-formaldehyde resin wall material was generated in the prepared microcapsules. The $1730 \mathrm{~cm}^{-1}$ was the characteristic peak of $\mathrm{C}=\mathrm{O}$, proving the existence of waterborne acrylic resin in microcapsules. No peak disappeared or appeared, indicating that there was no distinction in the composition of the coating with different concentrations of microcapsules. 

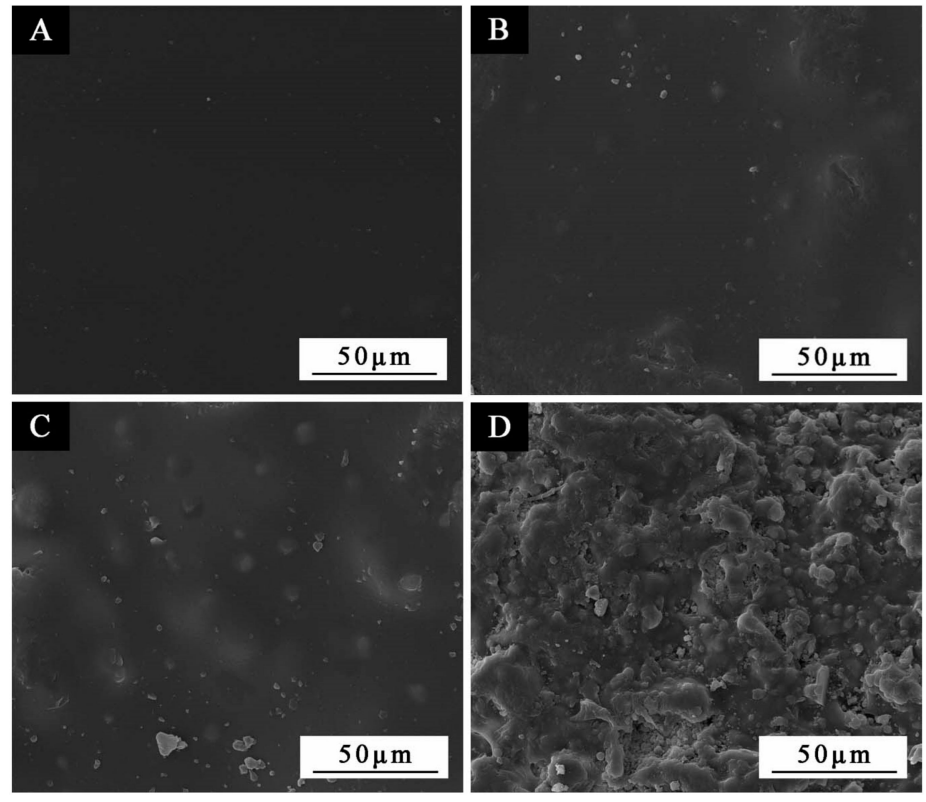

Figure 11. SEM of waterborne primer coating with different concentrations of microcapsules (core-wall ratio is $0.58: 1$ ). (A) $0 \%$; (B) $5.0 \%$; (C) $10.0 \%$; (D) $25.0 \%$.
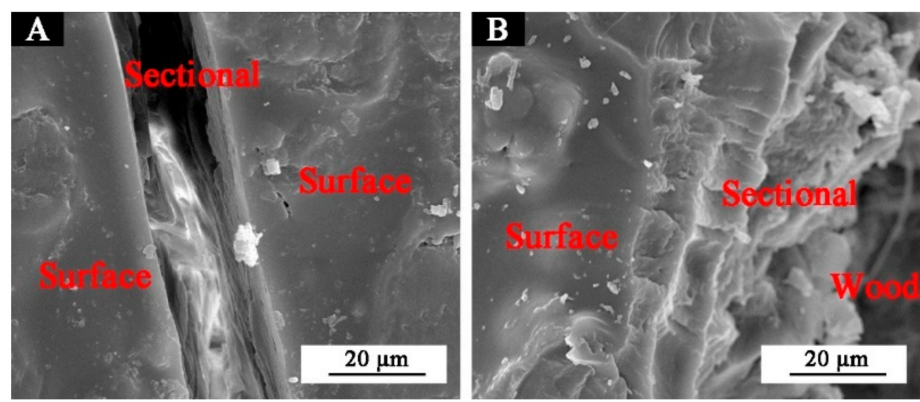

Figure 12. Cross-sectional SEM of waterborne primer coating with $10.0 \%$ concentration of microcapsules (core-wall ratio is 0.58:1). (A) Surface and section; (B) coating surface, section and wood.

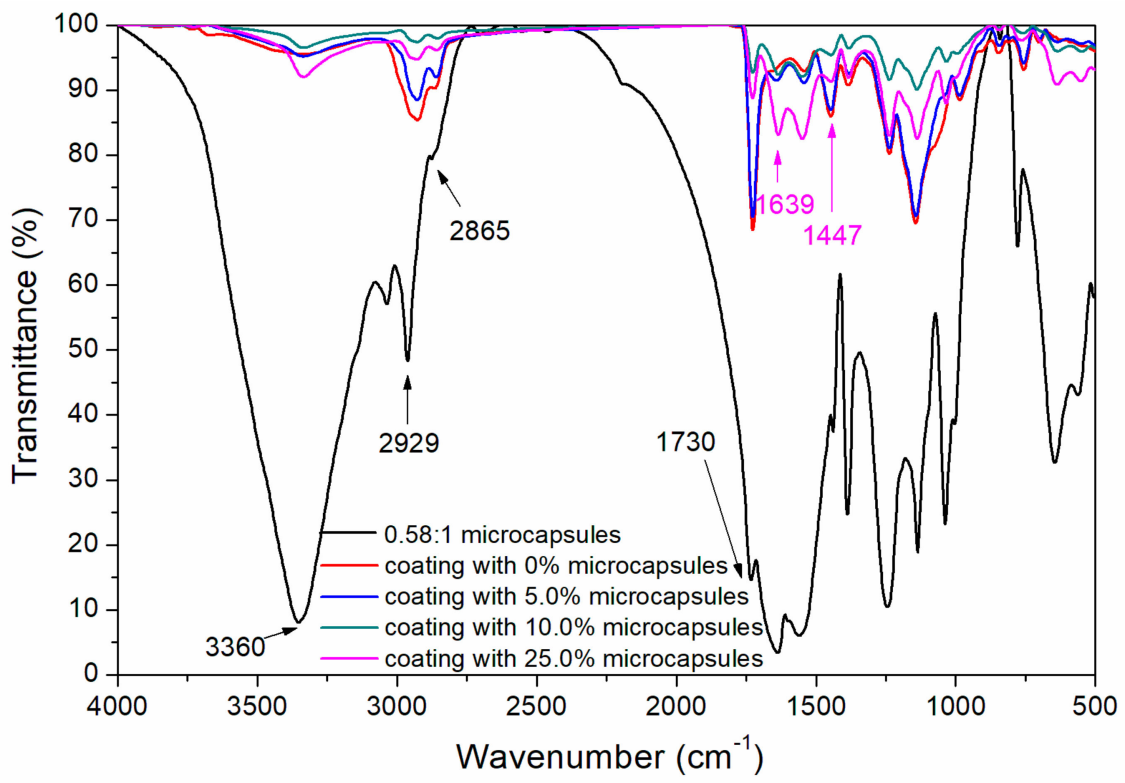

Figure 13. FTIR of waterborne primer coating with different concentrations of microcapsules (the core-wall ratio is $0.58: 1$ ). 


\subsection{Analysis of Self-Healing Performance of Waterborne Coating with Microcapsules}

According to the above performance test, it was concluded that the coating containing $10.0 \%$ microcapsules with 0.58:1 core-wall ratio was better, so it was further tested for self-healing experiment. Figure 14A is the OM image taken immediately after the scalpel and Figure 14B was the OM image after one day healing by microcapsules. According to the comparison before and after healing, the scratch width decreased from $19.7 \mu \mathrm{m}$ before healing to $8.92 \mu \mathrm{m}$ after one day healing. The results showed that the wood coating with waterborne acrylic-resin-filled urea-formaldehyde-based microcapsules with $0.58: 1$ core-wall ratio had a certain self-healing effect. The repair mechanism of the microcapsules (Figure 15) belonged to embedded self-healing method. According to the simulated biological damage repair schematic diagram, the microcracks generated by the coating are automatically repaired by the repair agent (core material). Under the external action, the wall of the microcapsules (urea formaldehyde resin) broke and the repair agent (waterborne acrylic resin) was released to the crack surface under the action of capillary. Then, the repair agent itself can polymerize at room temperature at the interface of wood waterborne coating, to bond the cracks and heal the cracks [28].
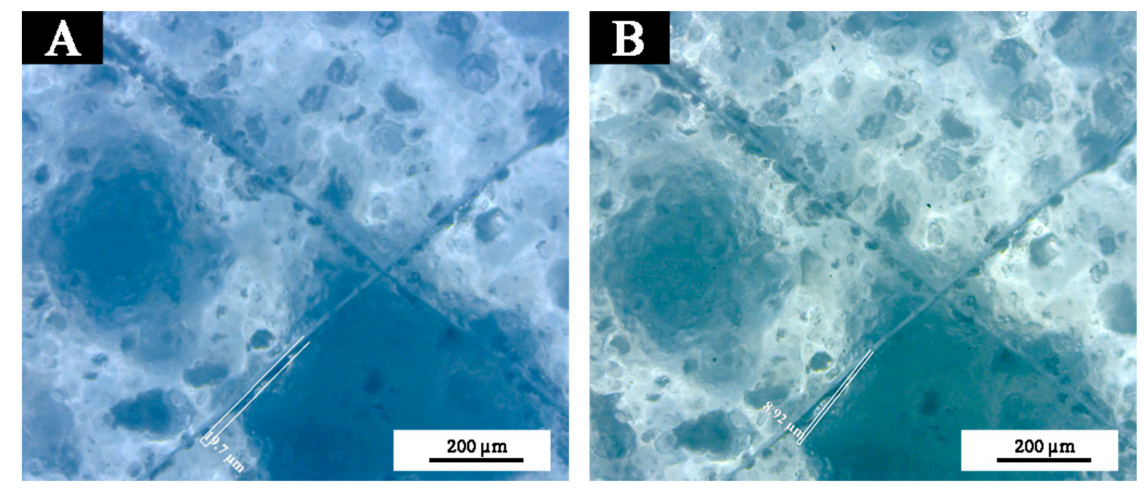

Figure 14. OM of waterborne coating with $10.0 \%$ concentration of microcapsules (core-wall ratio is 0.58:1). (A) Before healing; (B) after healing.

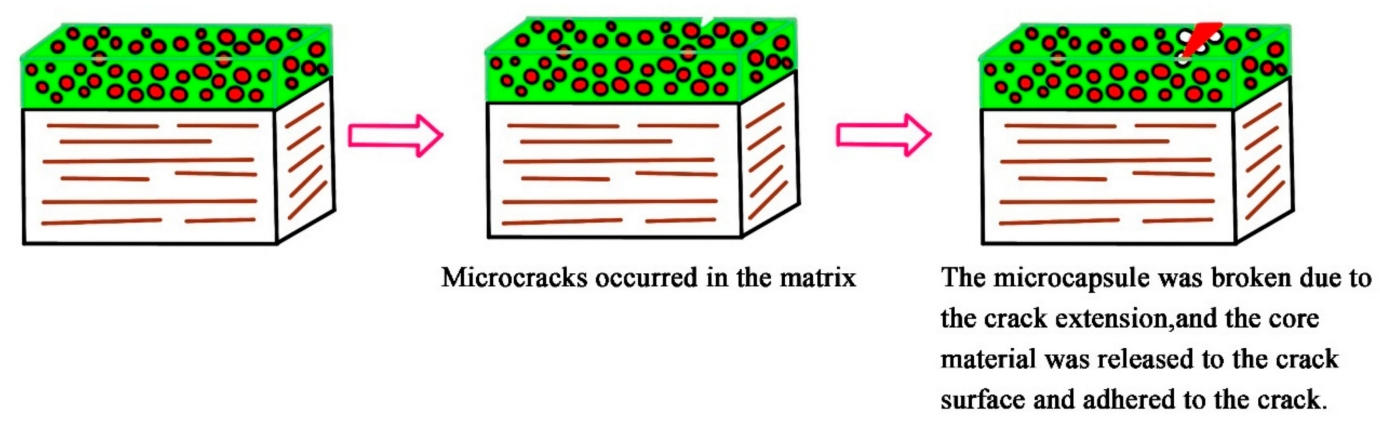

Figure 15. Self-healing mechanism of waterborne coating with microcapsules on the surface of European linden.

\subsection{Analysis of Antiaging Performance of Waterborne Coating with Microcapsules}

The antiaging results are shown in Table 9. The chroma difference and gloss of the coating without microcapsules were more obvious. After the aging and stability test, the chroma difference was 6.4, and the gloss decreased from 46.1 to 43.5. However, the chroma difference of the coating with $10.0 \%$ microcapsule was 3.5 , and the gloss of the coating was basically unchanged, which proved that the waterborne coating had the good antiaging effect after adding microcapsules. From Table 4, the chroma difference value 3.5 belonged to slight discoloration, while the chroma difference value 6.4 was apparent discoloration. In addition, the gloss of the coating without microcapsules decreased by $2.6 \%$ after aging. However, the gloss of the coating with $10.0 \%$ microcapsules decreased by $0.8 \%$. Compared with the coating with $10.0 \%$ microcapsules, the coating film without microcapsules lost 
more lighter, indicating that the coating with microcapsules had a certain antiaging effect and the addition of microcapsules could effectively inhibit the aging of coating.

Table 9. Effect of Aging and Stability Test on the Chroma Difference and Gloss Value of Waterborne Coating.

\begin{tabular}{|c|c|c|c|c|c|c|c|c|c|}
\hline $\begin{array}{c}\text { Sample } \\
(\#)\end{array}$ & $\begin{array}{c}\text { Microcapsule } \\
\text { Concentration (\%) }\end{array}$ & $\begin{array}{l}\text { State of the } \\
\text { Coating }\end{array}$ & $\begin{array}{l}\text { Gloss } \\
(\%)\end{array}$ & \multicolumn{5}{|c|}{ Chroma Value } & $\Delta \mathrm{E}$ \\
\hline 7 & 0 & $\begin{array}{c}\text { before aging } \\
\text { after aging }\end{array}$ & $\begin{array}{l}46.1 \\
43.5\end{array}$ & $\begin{array}{c}\mathrm{L}_{1} \\
77.3 \pm 0 \\
\mathrm{~L}_{2} \\
80.7 \pm 0\end{array}$ & $\begin{array}{c}\mathrm{a}_{1} \\
8.7 \pm 0 \\
\mathrm{a}_{2} \\
8.0 \pm 0\end{array}$ & $\begin{array}{c}\mathrm{b}_{1} \\
26.7 \pm 0 \\
\mathrm{~b}_{2} \\
21.3 \pm 0\end{array}$ & $\begin{array}{c}\mathrm{c}_{1} \\
28.1 \pm 0 \\
\mathrm{c}_{2} \\
22.8 \pm 0\end{array}$ & $\begin{array}{c}\mathrm{H}_{1} \\
71.9 \pm 0 \\
\mathrm{H}_{2} \\
69.3 \pm 0\end{array}$ & $\begin{array}{c}- \\
6.4 \pm 0\end{array}$ \\
\hline 8 & 10.0 & $\begin{array}{c}\text { before aging } \\
\text { after aging }\end{array}$ & $\begin{array}{l}25.9 \\
25.1\end{array}$ & $\begin{array}{c}\mathrm{L}_{1} \\
79.1 \pm 0 \\
\mathrm{~L}_{2} \\
81.9 \pm 0\end{array}$ & $\begin{array}{c}\mathrm{a}_{1} \\
8.8 \pm 0 \\
\mathrm{a}_{2} \\
7.1 \pm 0\end{array}$ & $\begin{array}{c}\mathrm{b}_{1} \\
30.8 \pm 0 \\
\mathrm{~b}_{2} \\
29.6 \pm 0\end{array}$ & $\begin{array}{c}\mathrm{c}_{1} \\
32.1 \pm 0 \\
\mathrm{c}_{2} \\
30.5 \pm 0\end{array}$ & $\begin{array}{c}\mathrm{H}_{1} \\
74.0 \pm 0 \\
\mathrm{H}_{2} \\
74.4 \pm 0\end{array}$ & $\begin{array}{c}- \\
3.5 \pm 0\end{array}$ \\
\hline
\end{tabular}

Figure 16 shows the SEM of the coating before and after the aging and stability test. Before the antiaging test (Figure 16A,B), the coating without microcapsule was smooth, and the coating with $10.0 \%$ microcapsules had obvious particles. The increasing concentration led to the increase of the particles, which was also the main reason for the lessening of the gloss [20]. The damage of the coating without microcapsules was obvious after the aging and stability experiment. As shown in Figure 14, after the antiaging test (Figure 16C,D), there were blisters on the surface of the coating without microcapsules or $10.0 \%$ microcapsules. The larger blister crack diameter was close to $40.0 \mu \mathrm{m}$ (Figure 16C), but the diameter of the blisters on the coating with microcapsules (Figure 16D) only had a small number of bubbles and significantly smaller than that of the coating without microcapsules, which showed that the microcapsules had a certain inhibition on the generation of cracks. According to the comparison of SEM images, before the antiaging test, no matter whether the coating with or without microcapsules was added, there was no bubble phenomenon on the surface, so these bubbles were caused by the impact of the antiaging test environment. That was, these cracks were caused by the impact of environmental factors. The addition of microcapsules can inhibit or repair the crack growth, so the bubble becomes smaller. This may be due to that the microcapsules can repair the microcracks in time, so the aging resistance is improved.
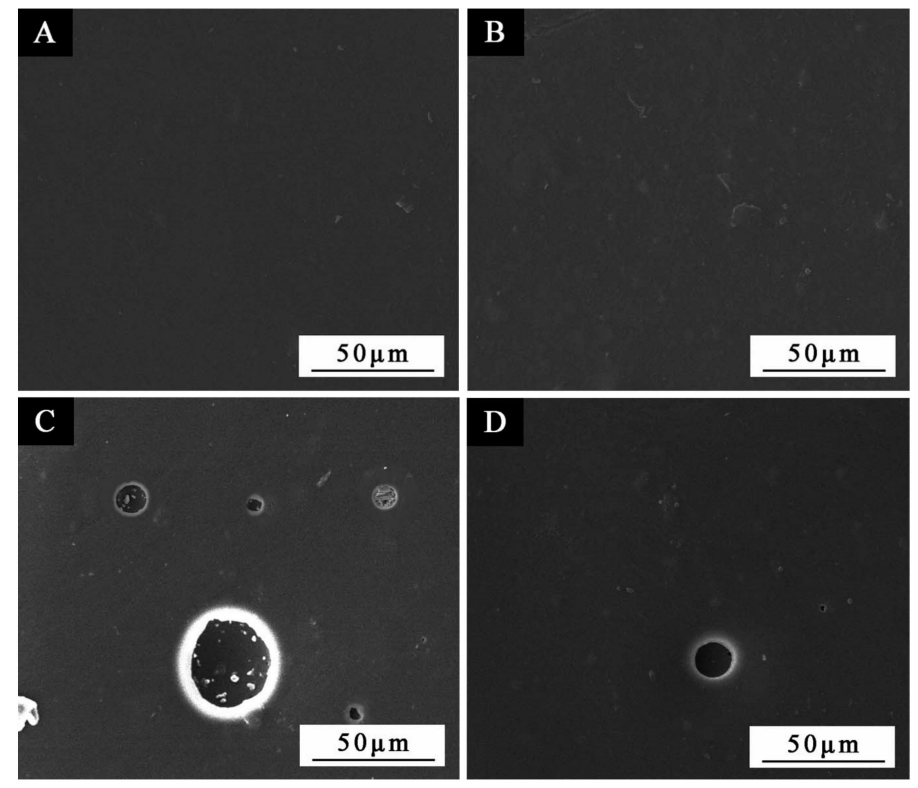

Figure 16. SEM of waterborne coating with $0 \%$ and $10.0 \%$ concentration of microcapsules (core-wall ratio is $0.58: 1$ ) before and after the aging and stability test. Before (A) $0 \%$; (B) $10.0 \%$; after (C) $0 \%$; (D) $10.0 \%$. 


\section{Conclusions}

The morphology of the $0.58: 1$ microcapsule was better. When the concentrations of the microcapsules were $0-10.0 \%$, it had no apparent effect on the chroma difference of coating, and the gloss and adhesions were better. When the concentrations of microcapsules were $10.0-15.0 \%$, and the core-wall ratio was $0.58: 1$, the coating hardness was higher. As the concentrations were $10.0-15.0 \%$, the impact resistance was stronger, and the elongation at break of the coating with the microcapsule of $0.58: 1$ core-wall ratio was the highest. For the microcapsules with $0.58: 1$ core-wall ratio, the concentration did not affect the coating liquid resistance. At $10.0 \%$ concentration, the water-contact angle of the coating added with $0.58: 1$ microcapsule possessed a high water-contact angle of $68.6^{\circ}$. There was no distinction in the composition of the coating with different concentrations of microcapsules. The microcapsules had a certain self-healing and aging resistance on the coating. From the perspective of comprehensive analysis, when the core-wall ratio of microcapsules was $0.58: 1$, the waterborne primer coating with $10.0 \%$ concentration of microcapsules had a good overall performance. This study offers a new way in using self-healing microcapsules for waterborne wood coating.

Author Contributions: Conceptualization, X.Y.; methodology, X.Y.; validation, X.Y.; resources, X.Y.; data curation, X.Y.; writing-Original draft preparation, X.Y.; supervision, X.Y.; data analysis, L.W. and X.Q.; investigation, L.W.; writing-Review and editing, L.W. All authors have read and agreed to the published version of the manuscript.

Funding: This project was partly supported by [General Program of Jiangsu Natural Science Foundation in 2020] (Project title: Study on the relationship between microstructure control of self-repairing coating and wood based on microcapsule technology) and the Youth Science and Technology Innovation Fund of Nanjing Forestry University, Grant Number (CX2016018).

Conflicts of Interest: The authors declare no conflict of interest.

\section{References}

1. Xiong, X.Q.; Niu, Y.T.; Yuan, Y.Y.; Zhang, L.T. Study on dimensional stability of veneer rice straw particleboard. Coatings 2020, 10, 558. [CrossRef]

2. Ozgenc, O.; Durmaz, S.; Sahin, S.; Boyaci, I.H. Evaluation of the weathering resistance of waterborne acrylicand alkyd-based coatings containing HALS, UV absorber, and bark extracts on wood surfaces. J. Coat. Technol. Res. 2020, 17, 461-475. [CrossRef]

3. Xu, W.; Fang, X.Y.; Han, J.T.; Wu, Z.H.; Zhang, J.L. Effect of coating thickness on sound absorption property of four wood species commonly used for piano soundboards. Wood Fiber Sci. 2020, 52, 28-43. [CrossRef]

4. Khanjani, J.; Hanifpour, A.; Pazokifard, S.; Zohuriaan-Mehr, M.J. Waterborne acrylic-styrene/PDMS coatings formulated by different particle sizes of PDMS emulsions for outdoor applications. Prog. Org. Coat. 2020, 141, 105267. [CrossRef]

5. Wan, T.; Chen, D.J. Preparation of beta-cyclodextrin reinforced waterborne polyurethane nanocomposites with excellent mechanical and self-healing property. Compos. Sci. Technol. 2018, 168, 55-62. [CrossRef]

6. Wang, F.F.; Feng, L.J.; Lu, M. Mechanical properties of multi-walled carbon nanotube/waterborne polyurethane conductive coatings prepared by electrostatic spraying. Polymers 2019, 11, 714. [CrossRef]

7. Yan, X.X.; Wang, L.; Qian, X.Y. Effect of urea-formaldehyde-coated epoxy microcapsule modification on gloss, toughness and chromatic distortion of acrylic copolymers waterborne coating. Coatings 2019, 9, 239. [CrossRef]

8. Cheng, L.S.; Ren, S.B.; Lu, X.N. Application of eco-friendly waterborne polyurethane composite coating incorporated with nano cellulose crystalline and silver nano particles on wood antibacterial board. Polymers 2020, 12, 407. [CrossRef]

9. Yang, F.; Wu, Y.; Zhang, S.Q.; Zhang, H.M.; Zhao, S.L.; Zhang, J.L.; Fei, B.H. Mechanical and thermal properties of waterborne polyurethane coating modified through one-step cellulose nanocrystals/graphene materials sols method. Coatings 2020, 10, 40. [CrossRef]

10. Nan, F.; Liu, C.B.; Pu, J.B. Anticorrosive performance of waterborne epoxy coatings containing attapulgite/graphene nanocomposites. Surf. Topogr.-Metrol. 2019, 7, 024002. [CrossRef] 
11. Wu, Y.; Wu, J.M.; Wang, S.Q.; Feng, X.H.; Chen, H.; Tang, Q.W.; Zhang, H.Q. Measurement of mechanical properties of multilayer waterborne coatings on wood by nanoindentation. Holzforschung 2019, 73, 871-877. [CrossRef]

12. Song, Y.K.; Lee, T.H.; Lee, K.C.; Choi, M.H.; Kim, J.C.; Lee, S.H.; Noh, S.M.; Park, Y.I. Coating that self-reports cracking and healing using microcapsules loaded with a single AIE fluorophore. Appl. Surf. Sci. 2020, 511, 145556. [CrossRef]

13. Chen, K.L.; Zhou, J.L.; Che, X.G.; Zhao, R.Y.; Gao, Q. One-step synthesis of core shell cellulose-silica/ n-octadecane microcapsules and their application in waterborne self-healing multiple protective fabric coatings. J. Colloid Interf. Sci. 2020, 566, 401-410. [CrossRef] [PubMed]

14. Ma, Y.X.; Zhang, Y.R.; Liu, J.T.; Ge, Y.J.; Yan, X.N.; Sun, Y.; Wu, J.; Zhang, P. GO-modified double-walled polyurea microcapsules/epoxy composites for marine anticorrosive self-healing coating. Mater. Des. 2020, 189, 108547. [CrossRef]

15. Ying, Y.; Liu, Z.Q.; Fan, J.J.; Wei, N.; Guo, X.Y.; Wu, Y.P.; Wen, Y.; Yang, H.F. Micelles-based self-healing coating for improved protection of metal. Arab. J. Chem. 2018, 13, 3137-3148. [CrossRef]

16. Saman, N.M.; Ang, D.T.C.; Shahabudin, N.; Gan, S.N.; Basirun, W.J. UV-curable alkyd coating with self-healing ability. J. Coat. Technol. Res. 2019, 16, 465-476. [CrossRef]

17. Gao, P.Z.; Wu, M.J.; Li, B.J.; Liu, Y.L. Structure characterization and oxidation mechanism study of porous biomorphic carbon template derived from basswood. Mater. Res. Bull. 2008, 44, 644-648. [CrossRef]

18. Qian, J.M.; Wang, J.P.; Jin, Z.H. Preparation of biomorphic SiC-ceramics by the reactive infiltration on of Si into carbon template derived from basswood. Rare Metal. Mat. Eng. 2004, 33, 1065-1068.

19. Yan, X.X.; Qian, X.Y.; Chang, Y.J. Preparation and characterization of urea formaldehyde @ epoxy resin microcapsule on waterborne wood coatings. Coatings 2019, 9, 475. [CrossRef]

20. Relosi, N.; Neuwald, O.A.; Zattera, A.J.; Piazza, D.; Kunst, S.R.; Birriel, E.J. Effect of addition of clay minerals on the properties of epoxy/polyester powder coatings. Polimeros 2018, 28, 355-367. [CrossRef]

21. Deflorian, F.; Fedel, M.; di Gianni, A.; Bongiovanni, R.; Turri, S. Corrosion protection properties of new UV curable waterborne urethane acrylic coatings. Corros. Eng. Sci. Techn. 2008, 43, 81-86. [CrossRef]

22. Yan, X.X.; Qian, X.Y.; Lu, R.; Miyakoshi, T. Synergistic effect of addition of fillers on properties of interior waterborne UV-curing wood coatings. Coatings 2018, 8, 9. [CrossRef]

23. Zhang, K.; Zhou, Q.; Ye, H.M. Optimizing the Preparation of semi-crystalline paraffin/poly (urea-formaldehyde) microcapsules for thermal energy storage. Appl. Sci.-Basel. 2019, 9, 599. [CrossRef]

24. Mirabedini, S.M.; Kiamanesh, A. The effect of micro and nano-sized particles on mechanical and adhesion properties of a clear polyester powder coating. Prog. Org. Coat. 2013, 76, 1625-1632. [CrossRef]

25. Smikalla, M.; Mescher, A.; Walzel, P.; Urbanetz, N.A. Impact of excipients on coating efficiency in dry powder coating. Int. J. Pharmaceut. 2011, 405, 122-131. [CrossRef]

26. Li, Y.; Wang, G.Q.; Guo, Z.H.; Wang, P.Q.; Wang, A.M. Preparation of microcapsules coating and the study of their bionic anti-fouling performance. Materials 2020, 13, 7. [CrossRef]

27. Yan, X.X.; Qian, X.Y.; Chang, Y.J.; Lu, R.; Miyakoshi, T. The effect of glass fiber powder on the properties of waterborne coatings with thermochromic ink on a Chinese Fir surface. Polymers 2019, 11, 1733. [CrossRef]

28. Mirabedini, S.M.; Dutil, I.; Gauquelin, L.; Yan, N.; Farnood, R.R. Preparation of self-healing acrylic latex coatings using novel oil-filled ethyl cellulose microcapsules. Prog. Org. Coat. 2015, 85, 168-177. [CrossRef]

(C) 2020 by the authors. Licensee MDPI, Basel, Switzerland. This article is an open access article distributed under the terms and conditions of the Creative Commons Attribution (CC BY) license (http://creativecommons.org/licenses/by/4.0/). 